\title{
PROSPECÇÃO TECNOLÓGICA DE PATENTES PARA DETERMINAÇÃO DE MÉTODOS UTILIZADOS PARA ANÁLISE DE MATÉRIA-PRIMA NA PRODUÇÃ̃O DE BIODIESEL
}

\author{
Saionara Luna, Marilena Meira, Cristina M. Quintella \\ Universidade Federal da Bahia, Rua Barão de Geremoabo, s/n , Campus Universitário de Ondina, \\ Salvador-BA. Cep.40.170-290 (saionaraluna@gmail.com)
}

\begin{abstract}
RESUMO
O biodiesel é um combustível alternativo ao combustível fóssil sendo obtido de fontes renováveis (soja, mamona, girassol) e assim, emite menos poluente que o diesel. O desenvolvimento de novos métodos analíticos para determinação da qualidade do bidiesel, é uma necessidade atual, visto que o biodiesel está sendo, considerávelmente usado como combustível. Visando fazer um mapeamento de patentes relacionadas à métodos para determinação da qualidade em foco na qualidade da matéria-prima, foi realizada esta prospecção tecnológica, em banco de patentes, dando ênfase em métodos óticos. A metodologia da busca consistiu na associação da palavra-chave substance* com o código G01N21, que se refere a métodos óticos.
\end{abstract}

PALAVRAS-CHAVE: Matéria prima, óleo, método ótico, combustíveis.

\section{ABSTRACT}

Biodiesel is an alternative fuel to fossil fuel being obtained from renewable sources (soybean, rapeseed, sunflower) and thus emits less pollution than diesel. The development of new analytical methods for determining the quality of bidiesel is a present need, since biodiesel is being considerably used as fuel. Aiming to do a mapping of patents related to methods for determining the quality, focus on the quality of the raw material, was held this technological forecasting in stock patents, focusing on optical methods. The methodology consisted of the search keyword substance* association with the code G01N21, which refers to optical methods.

KEYWORDS: Raw material, oil, optic method, Fuels.

Área tecnológica: Biocombustíveis, Análise de qualidade de materiais 


\section{INTRODUÇÃO}

A qualidade da matéria-prima utilizada na indústria é de fundamental importância para a qualidade do biodiesel $^{1}$, principalmente em função do rendimento obtido e do custo da produção em que a matériaprima contribui com cerca de $70-95 \%$ do custo total. Para se aferir tal qualidade, um dos parâmetros geralmente verificado é o grau de oxidação. A suscetibilidade dos óleos e gorduras à oxidação está relacionada com o nível de insaturação da cadeia carbônica do ácido graxo. Quanto mais insaturada a cadeia, mais suscetível será à oxidação. Esta é uma reação em cadeia por radicais livres e é acelerada pelo calor e pela presença de metais. No óleo comestível a oxidação afeta a cor, sabor e a qualidade nutricional. No combustível, a oxidação provoca mudanças principalmente na acidez e aumento da viscosidade devido à formação de gomas insolúveis, que torna o combustível inadequado para uso veicular $^{3}$. Em função da quase total ausência de antioxidantes, as gorduras animais ${ }^{4}$ são mais susceptíveis à oxidação quando comparadas com os óleos vegetais, apesar das gorduras bovinas possuírem alta concentração de gorduras saturadas enquanto que nos óleos vegetais predominam os ácidos graxos monoinsaturados e poliinsaturados. Além do problema associado à baixa estabilidade à oxidação, o uso de altas concentrações de gorduras animais pode elevar os custos com energia elétrica na produção de biodiesel devido aos altos pontos de fusão das gorduras saturadas que na temperatura ambiente se solidificam formando incrustações e entupimentos nas tubulações.

A qualidade do óleo está relacionado com a química de oxidação a partir do qual foram obtidos, porque a cadeia de ácidos graxos não é alterada durante o processo químico no qual ácidos graxos são transesterificados em ésteres alquílicos. Entre os fatores que afetam a velocidade de oxidação incluemse a concentração de oxigênio, o número de insaturações na cadeia, a presença de antioxidantes, presença de metais, a temperatura e a luz. A estabilidade oxidativa de um óleo ou biodiesel pode ser favorecida pelo maior teor de ácidos graxos saturados (Quintella et al., 2009). No entanto, muitos dos óleos de origem vegetal contêm ácidos graxos de cadeia insaturada, como os ácidos linoléico e linolênico, os quais causam a instabilidade à oxidação de óleos e biodiesel. Quanto maior o número de insaturações na cadeia do ácido graxo mais suscetível ele será à oxidação. Isomerização de cis para trans pode afetar a estabilidade oxidativa porque a dupla na configuração trans apesar de ser mais estável é mais susceptível à oxidação que a dupla em cis (Berthiaume, 2006).

O principal método atualmente em uso para a determinação da estabilidade oxidativa é o método Rancimat que mede o período de indução (Berthiaume, 2006). Outros métodos conhecidos são a medição do índice de acidez, índice de peróxido, análise sensorial, determinação de dienos conjugados, valor de carbonila, análise de voláteis, etc.

Este trabalho tem por objetivo apresentar o panorama do estágio atual e identificar as tendências tecnológicas de desenvolvimento cientifico e tecnológico relacionados ao desenvolvimento de métodos óticos para determinação da qualidade de amostras incluindo óleos e o próprio biodiesel. Através do mapeamento das patentes são avaliadas as perspectivas do uso de métodos óticos para a determinação da qualidade da matéria-prima e sugestões de estudos e tecnologias a serem desenvolvidas. 


\section{METODOLOGIA}

A base de dados escolhida foi a Escritório Europeu (Espacenet $\left.{ }^{\circledR}\right)$ conhecido também como EPO, que é uma base de acesso livre usualmente escolhida para estudo de prospecção tecnológica. Foi também feita a associação das palavras-chaves substance* oil* e a associação das palavras-chaves substance* oil* também com o código da Classificação Internacional de Patentes (CIP) G01N21 visando especificar o método ótico mais utilizado na analise de qualidade do biodiesel.

A Tabela 1 mostra escopo utilizado para a pesquisa de patentes realizada através do banco de patentes do Espacenet ${ }^{\circledR}$. A coleta de dados foi realizada no período de abril a junho de 2011 objetivando mapear o uso de métodos óticos na determinação da qualidade do biodiesel. A metodologia consistiu na associação da palavra-chave substance* oil* com o código G01N21, que se refere a métodos óticos.

Tabela 1: Palavras-chave e códigos da classificação internacional de patentes (CIP) utilizados para a busca e número de documentos de patentes encontrados na base de dados européia.

\begin{tabular}{c|c|c|c|c|c|c|c|c}
\hline Substance*1 $^{*}$ & Fat* $^{*}$ & Biodiese* $^{*}$ & Diese* & Oil* & Fluoresc* & C10G1 & G01N212 & Total \\
\hline $\mathrm{X}$ & & & $\mathrm{X}$ & & & & & 2170 \\
\hline $\mathrm{X}$ & & & & $\mathrm{X}$ & & & & 44189 \\
\hline $\mathrm{X}$ & & & & & $\mathrm{X}$ & & & 0 \\
\hline $\mathrm{X}$ & & & & $\mathrm{X}$ & & $\mathrm{X}$ & & 393 \\
\hline $\mathrm{X}$ & & & & $\mathrm{X}$ & $\mathrm{X}$ & $\mathrm{X}$ & & 0 \\
\hline $\mathrm{X}$ & & & $\mathrm{X}$ & & & $\mathrm{X}$ & & 21 \\
\hline $\mathrm{X}$ & & & & $\mathrm{X}$ & $\mathrm{X}$ & & $\mathrm{X}$ & 27 \\
\hline $\mathrm{X}$ & & & $\mathrm{X}$ & & & & $\mathrm{X}$ & 13 \\
\hline $\mathrm{X}$ & & & & $\mathrm{X}$ & & & $\mathrm{X}$ & 187 \\
\hline & & & $\mathrm{X}$ & $\mathrm{X}$ & & & $\mathrm{X}$ & 27 \\
\hline & $\mathrm{X}$ & $\mathrm{X}$ & & $\mathrm{X}$ & & & & 3 \\
\hline
\end{tabular}

Fonte: Autoria própria, 2012.

${ }^{1}$ utilizando o conectivo "and”

${ }^{2}$ G01N21: Investigação ou análise de materiais pela utilização de meios óticos, isto é, usando a luz infra-vermelha, visível ou ultra-violeta.

${ }^{3}$ C10G1: Produção de misturas líquidas de hidrocarboneto a partir de xisto betuminoso, de arenitos, ou de matérias carbonáceas solidas não fusíveis ou similares. 


\section{RESULTADOS E DISCUSSÃO}

Em relação à evolução anual de depósitos de patentes, foi observado que as primeiras quatro patentes depositadas foram no ano de 1972. Foram duas do Japão uma dos EUA e a outra da Suécia. A Figura 1 apresenta a evolução anual do depósito de patentes relacionadas à tecnologia pesquisada de 1972 a 2009.

Observa-se que o depósito de patentes na área de estudo está concentrado nos últimos 10 anos com maior crescimento em 2001 (Figura 1).

Nos Estados Unidos a produção de biodiesel passou de 757 litros em 1999 para cerca de 80 milhões de litros em 2004. A frota de caminhões e tratores já tinha autorização para adicionar $20 \%$ de biodiesel ao diesel sem ainda legislação específica (BRASIL, 2007).

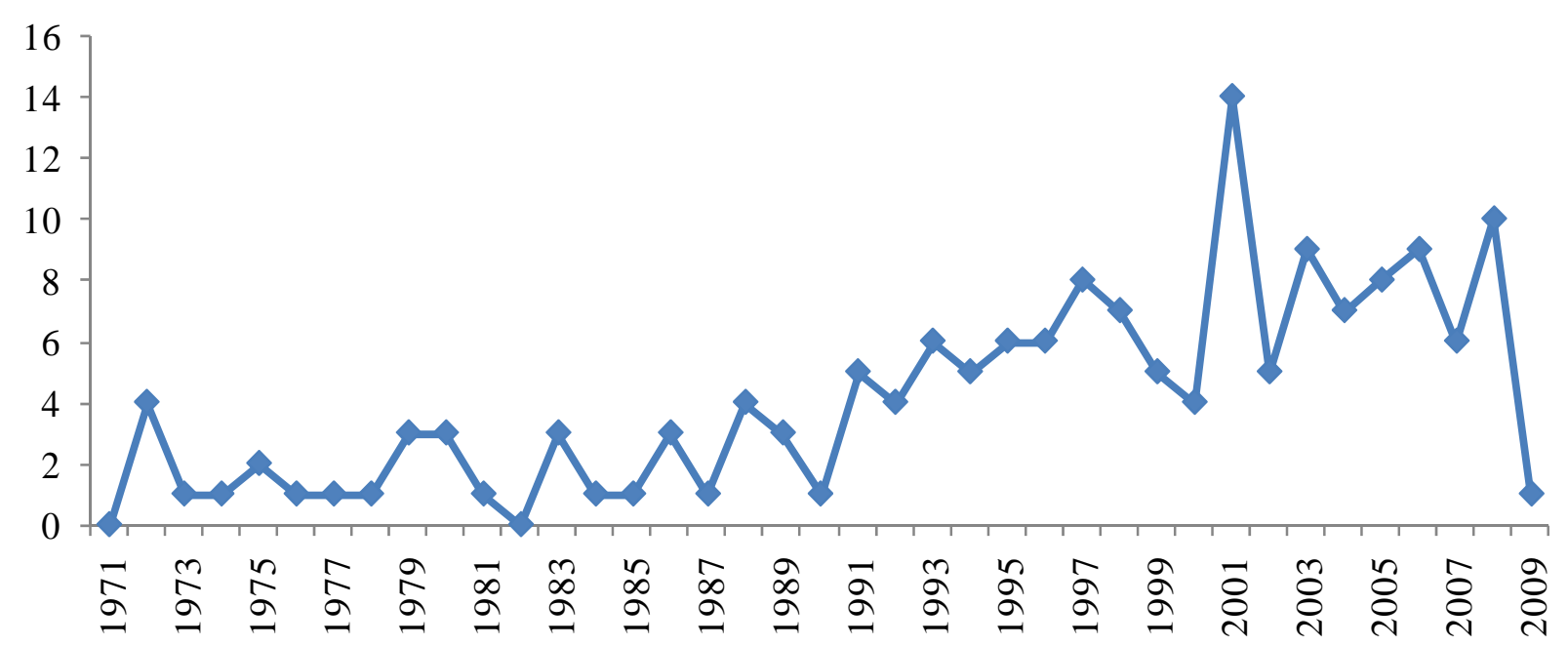

Figura 1: Evolução anual do depósito de patentes no Escritório Europeu de Patentes entre 1972 e 2009. Fonte: Autoria própria, 2012.

Nos primeiros 45 anos (1924-1969), foram depositadas apenas 13 patentes que estão ilustradas na Figura 1. Logo após o ano de 1972, podemos perceber que há um aumento crescente do número de patentes com o passar dos anos. De acordo com a Figura 1, não foram encontrados dados nos anos de 2010, 2011 e 2012, fato que está atribuído ao período de sigilo das patentes que são 18 meses. Podemos ainda inferir que ao longo dos anos o número de patentes relacionado ao tema estudado vem aumentando.

A Figura 2 diz respeito aos países que mais depositaram patentes com o tema estudado.

O Japão e a França são os grandes detentores da tecnologia relativa ao uso de métodos óticos para a determinação do uso de métodos óticos para analise de matéria-prima. Através do uso do software 
verificou-se também se havia ocorrência de relacionamento entre os países que mais depositaram patentes, ou seja, se eles faziam algum tipo de parceria para produção das patentes.

No entanto, como pode ser observado na Figura 3, cada país produziu suas patentes individualmente sem ocorrência de parcerias entre eles no que diz respeito ao tema estudado.

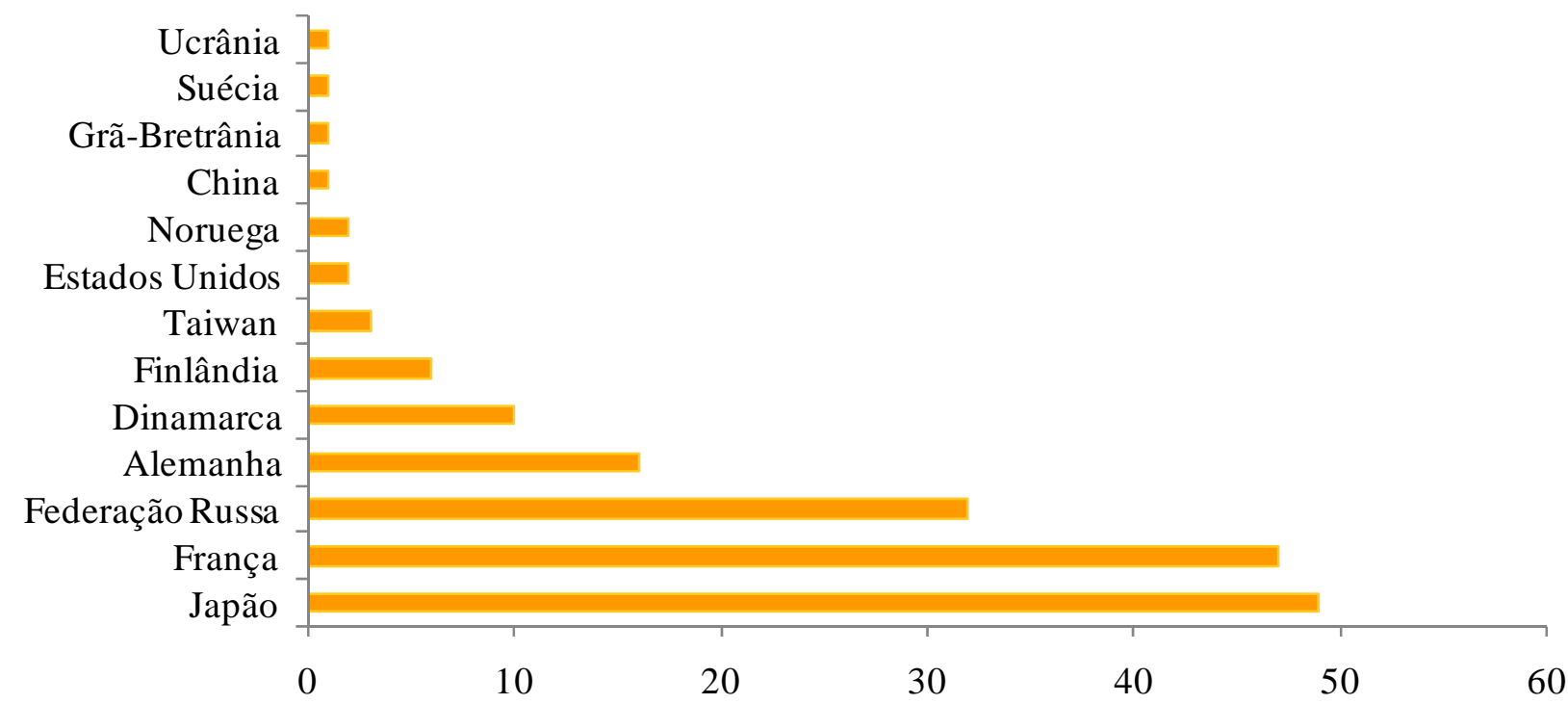

Figura 2: Distribuição dos depósitos de patentes por país de origem. Fonte: Autoria própria, 2012.

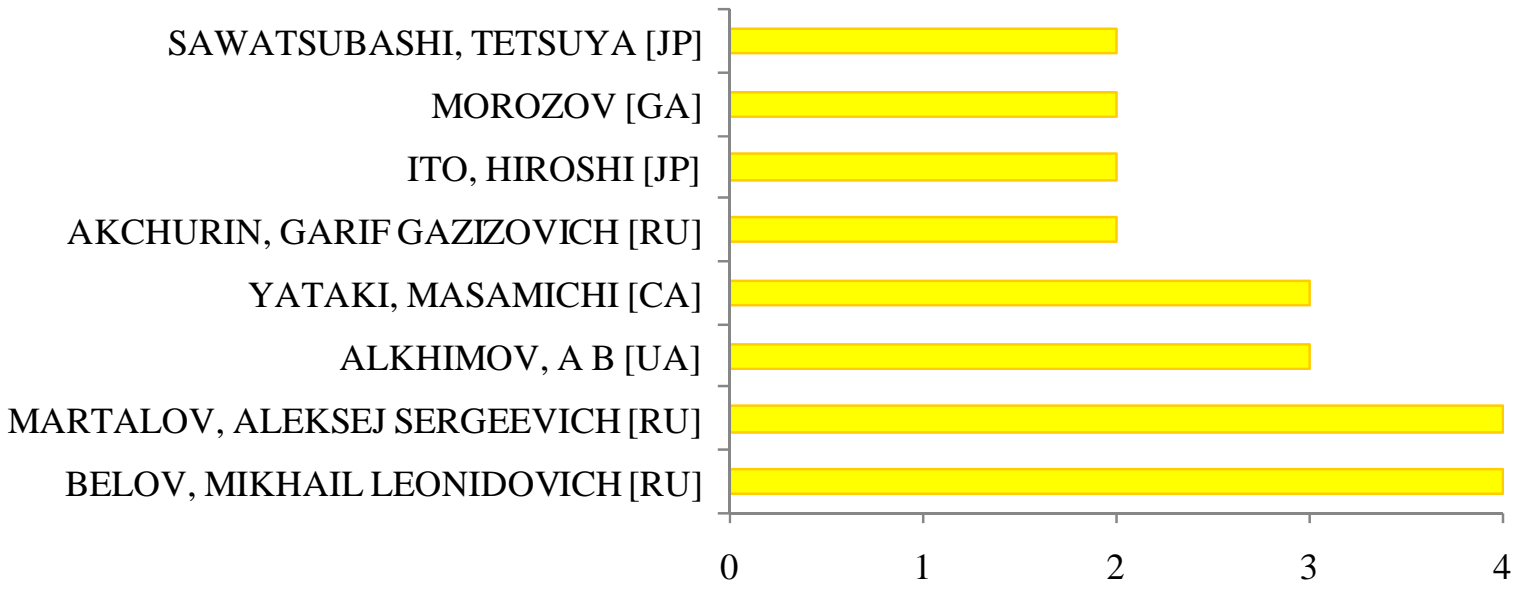

Figura 3: Número de patentes por depositantes. Fonte: Autoria própria, 2012. 
Entre os depositantes que mais produziram destaca-se Belov, Mikhail Leonidovich da Rússia com 4 patentes relacionadas ao tema estudado. Entre os depositantes destaca-se a empresa Mitsubishi Heavy uma das maiores produtoras de veículo de produtos relacionados como turbo compressores e máquinas para indústria de automóvel do Japão com 4 patentes depositadas. A Mitsubishi realiza pesquisas em diversas áreas de estudo, visando aumentar o campo de atuação.

Entre os depositantes foi também possível identificar o percentual dos países que tiveram mais de três patentes depositadas conforme mostrado na Figura 4.

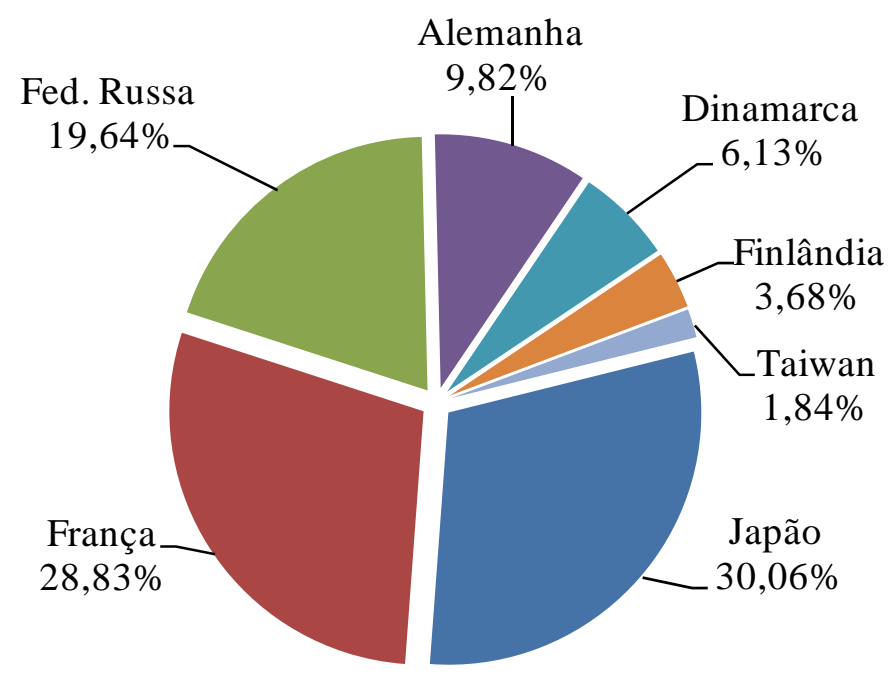

Figura 4: Percentual dos países que tiveram mais de três patentes depositadas. Fonte: Autoria própria, 2012.

Podemos observar que o Japão detém a maior fatia da tecnologia com 30,06\% das patentes. E a França tem 28,83\% das patentes e a Federação Russa 19,64\%. A partir destes dados podemos concluir que o interesse do Japão, da França e da Federação Russa pela pesquisa de novos métodos para determinação da qualidade da matéria-prima é similar entre si, tendo maior interesse o Japão. Os demais países mostram baixo interesse quando comparado com o Japão.

As empresas Japonesas foram as que mais depositaram patentes, como mostra a Figura 5. Com destaque a Mitsubishi com 4 patentes depositadas e a Shimadzu com 3 patentes relacionadas ao tema estudado.

Foram avaliadas 8 das patentes encontradas na pesquisa associando as palavras-chaves substance* e oil* com o código G01N21. Verificou-se através da leitura das patentes que a primeira se referia a um método simples para preparação de amostras pelas misturas de substancias onde é medida a concentração da substancia desejada. A substancia detectada por meio de dispositivos, ao lado de um 
detector contendo, reator de fluxo, multiplicador de foto-eletrônico, circuito de conversão com um gerador, uma fonte de misturas gasosas de referência e um display indicador, mostrando a presença de um valor de fundo de concentração para o efeito de detecção industrial.

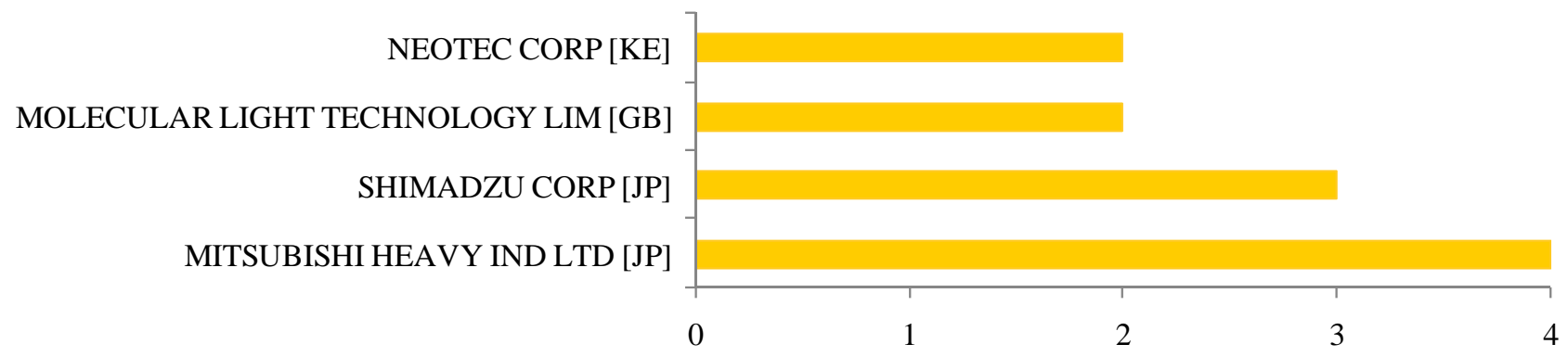

Figura 5: Número de patentes por depositantes de maior relevância. Fonte: Autoria própria, 2012.

A segunda patente refere-se a um procedimento que consiste na determinação de características espectrais da amostra na fronteira da faixa da zona de vazamento. São realizado cálculo de inclinação de acordo com característica e comprimento de onda de fuga do corte utilizado na avaliação quantitativa do grau de envelhecimento do óleo transformador.

A terceira patente apresenta um método para determinar a quantidade de substância polar, aumentando a dispersão dessa substância. Adicionando-se um surfactante, aumenta a absorbância ótica da substância polar para criar uma amostra, passando um espectro inicial de óptica através da amostra, medindo o especrtro resultante e depois relacionando a referência com esse espectro resultante para ter uma predeterminada calibração quantitativa óptico, e assim, determinar a concentração da substância polar com base nessa relação.

A quarta patente refere-se à invenção química ecológica aplicada à detecção de produtos de petróleo em ecossistemas aquáticos, obtendo uma maior confiabilidade e precisão da contaminação do óleo nesse ambiente.

A quinta patente refere-se a uma técnica de medição que pode ser usado para a detecção operatório de óleo e vazamentos de derivados de petróleo em mares interiores por feixes de água. O método inclui a irradiação de superfície de água em questão por feixe óptico pulsado com sintonizável comprimento de banda estreita do espectro de radiação refletida e comprimento de onda e obter na base desta dependência do índice de reflexão de sua derivada segunda com respeito ao comprimento de onda. A presença da película de óleo na superfície da água é determinada pela execução simultânea de duas relações que incluem índices de reflexão e a derivada segunda. Essa invenção torna possível detectar filmes finos de derivados de petróleo (com espessura de décimos de micros), com cerca de uma correta probabilidade de detecção. 
A sexta patente diz respeito a recepientes fabricados para separar os líquidos dos reagentes secos e para manter a estabilidade dos reagentes secos. Um líquido imiscível, como um óleo, é incluído para controlar o carregamento de materiais de processos, facilitar à mistura e reconstituição dos reagentes secos a evaporação limite a evaporação, aquecimento, controle de materiais de reação, concentra-se materiais de apoio sólido para evitar o entupimento das conexões de fluidos.

A sétima apresenta uma técnica utilizada na preservação de telas pintadas com tintas a óleo através da intensidade de radiação a laser com comprimento de onda na faixa de infravermelho e da intensidade de radiação a laser passando na superfície analisada, mantendo esse tipo de pintura, conservada.

A oitava patente trata de um método que relaciona a avaliação do motor de um veículo utilizando diesel por meio do controle de opacidade dos gases de escape. Com imagem em preto e branco (indicando a quantidade de fuligem negra sobre o branco) e extensão de iluminação de fundo preto (indicando vapores gasosos cinzas). Sendo que é uma técnica com baixo custo privilegiando assim a sua realização.

Com esta prospecção, foi possível verificar que o uso de métodos óticos para determinação da qualidade de óleos é explorado em diferentes finalidades, não só para a produção do biodiesel como para conservação de outras matérias, como a pintura a óleo. A maior desvantagem dos métodos óticos em relação aos métodos clássicos existentes atualmente diz respeito ao custo do equipamento. No entanto, a necessidade de sistemas de detecção mais versáteis, rápidos e eficientes para o monitoramento da oxidação de óleos e biodiesel pode estimular o desenvolvimento, em curto espaço de tempo, de uma grande variedade de tecnologias com o uso de métodos óticos que aliados as vantagens de maior precisão e exatidão dos resultados, a possibilidade de automatização e principalmente a maior rapidez analítica pode superar em muito a questão econômica. Os métodos óticos, principalmente a espectrofluorimetria e espectrometria no infravermelho revelam grandes perspectivas quanto a sua utilização no monitoramento da qualidade de óleos e biodiesel, sendo campos férteis de estudos e de tecnologias a serem desenvolvidas. Para suplementar estas técnicas, os biossensores podem se constituir em uma ferramenta promissora devido as suas características únicas, tais como: baixo custo relativo de construção, potencial para construção de equipamentos simples e portáteis, possibilidade de monitoramento no campo e facilidade de automação.

\section{CONCLUSÃO}

De acordo com a metodologia empregada neste estudo, foram encontrados 187 patentes que faziam referência a patentes relacionadas a métodos óticos e qualidade. E destas, uma parte relaciona-se a óleos, sendo que destas algumas se refere à método, dispositivo ou aparelho para monitorar a qualidade de óleos por técnicas espectroscópicas. Das técnicas espectroscópicas apenas espectroscopia de fluorescência e espectrometria no infravermelho foram citadas nas patentes. Os métodos óticos para determinar qualidade de óleos ainda são muito pouco utilizados consistindo de oportunidades para Pesquisa \& Desenvolvimento (P\&D), tendo alto potencial de gerar inovação. 


\section{REFERÊNCIAS}

http://www.technopolethetford.ca/FichiersUpload/Softsystem/NRCan-OLEOTEK-

StudyoftheRancimatTestMethodinMeasuringtheOxidationStabilityofBiodieselEstersandBlends.pdf.

Accessed in February 2011.

MONYEM, A.; VAN GERPEN, J. H.; Biomass \& Bioenergy 2001, 20, 317.

MONYEM, A.; VAN GERPEN, J. H.; Canakci, M.; Transactions Of The Asae 2001, 44, 35.

QUINTELLA, C.M.; TEXEIRA, L. S. G.; KORN, M. G. A.; COSTA NETO, P. R.; E. A. CASTRO, M. P. JESUS, C. A. C.; Cadeia do biodiesel da bancada à indústria: uma visão geral com prospecção de tarefas e oportunidades para P\&D\&I Quim. Nova v.32, p. 1-16, 2009

SENDZIKIENE, E., V. MAKAREVICIENE AND P. JANULIS; Polish Journal of Environmental Studies 2005, 14, 335.

www.exxonmobilchemical.com/. Acesso em: 2 de Julho de 2011 às 10:00 hs.

www.linkedin.com/company/symyx-technologies. Acesso em 2 de julho de 2011 às 16:00 hs. 